\title{
Optimum design of open pit mines
}

\section{L.M. Giannini}

A fundamental problem in open pit mine planning is that of determining the optimum ultimate pit limits of the mine. These limits are that pit contour which is the result of extracting a volume of material which maximises the difference between the value of extracted ore and the total extraction cost of ore and waste whilst satisfying certain practical operational requirements, such as, safe wall slopes. The determination of the optimum pit contour provides information which is essential in the evaluation of the economic potential of the mineral deposit.

A number of optimisation techniques have been proposed for determining the optimum pit contour. Of these techniques, those based on graph theory, linear programming and dynamic programming are mathematically rigorous, but only those based on graph theory are more suited to solving the three-dimensional problem. Unfortunately, direct application of these techniques to large ore-bodies may cause considerable difficulties because of the exceptionally high demand on computer storage and time requirements. Indeed, 25 years of research effort has not satisfactorily resolved these computational problems.

A major contribution of the work presented in this thesis is the successful implementation of a system of techniques to solve the graph theoretic model, particularly when applied to large ore-bodies. A measure of this success is the fact that pits, as much as seven times larger, may be designed with a given amount of computer storage, at a fraction of the time required by current software packages. The solution strategy presented involves the application of a modified Dinic's Maximum Flow algorithm, together with an efficient 'data reducing' technique. Computational results of these techniques applied on data from gold producing mines in Western Australia are used to demonstrate the success of this strategy.

The relationships between the rigorous pit optimisation techniques are also considered in this work. In particular, the Lerchs-Grossman graph-theoretic method is shown

Received 12 September, 1990.

Thesis submitted to Curtin University of Technology, April 1990. Degree approved, August 1990. Supervisor Dr L. Caccetta. This thesis has been classified as Confidential for a period of 10 years from 1 May 1990.

Copyright Clearance Centre, Inc. Serial-fee code: 0004-9729/91 \$A2.00+0.00. 
to be stepwise equivalent to a modified version of the Dual-Simplex Linear Programming technique and not as efficient as the Network Flow method.

School of Mathematics and Statistics

Curtin University of Technology

Kent Street

Bentley WA 6102

Australia 